Article

\title{
An Investigation of the Antioxidant Capacity in Extracts from Moringa oleifera Plants Grown in Jamaica
}

\author{
Racquel J. Wright ${ }^{1,2}$, Ken S. Lee ${ }^{3}$, Hyacinth I. Hyacinth ${ }^{4}$, Jacqueline M. Hibbert ${ }^{5}$, \\ Marvin E. Reid ${ }^{2}$, Andrew O. Wheatley ${ }^{1,6}$ and Helen N. Asemota 1,6,* \\ 1 Biotechnology Centre, University of the West Indies, Mona Kingston 8, Jamaica; \\ racq.wright@gmail.com (R.J.W.); awheatley@mset.gov.jm (A.O.W.) \\ 2 Caribbean Institute for Health Research, University of the West Indies, Mona Kingston 8, Jamaica; \\ marvin.reid@uwimona.edu.jm \\ 3 Department of Chemistry and Biochemistry, Jackson State University, Jackson, MS 39217, USA; \\ ken.s.lee@jsums.edu \\ 4 Department of Pediatrics, Aflac Cancer and Blood Disorder Center, Children's Healthcare of Atlanta and \\ Emory University, Atlanta, GA 30322, USA; hhyacinth@emory.edu \\ 5 Department of Microbiology, Biochemistry and Immunology, Morehouse School of Medicine, \\ 720 Westview Drive SW, Atlanta, GA 30310, USA; jhibbert@msm.edu \\ 6 Biochemistry Section, Department of Basic Medical Sciences, University of the West Indies, \\ Mona Kingston 8, Jamaica \\ * Correspondence: helen.asemota@uwimona.edu.jm; Tel.: +1-876-977-1828
}

Academic Editor: Milan S. Stankovic

Received: 18 September 2017; Accepted: 28 September 2017; Published: 23 October 2017

\begin{abstract}
Moringa oleifera trees grow well in Jamaica and their parts are popularly used locally for various purposes and ailments. Antioxidant activities in Moringa oleifera samples from different parts of the world have different ranges. This study was initiated to determine the antioxidant activity of Moringa oleifera grown in Jamaica. Dried and milled Moringa oleifera leaves were extracted with ethanol/water (4:1) followed by a series of liquid-liquid extractions. The antioxidant capacities of all fractions were tested using a 2,2-diphenyl-1-picrylhydrazyl (DPPH) assay. $\mathrm{IC}_{50}$ values (the amount of antioxidant needed to reduce $50 \%$ of DPPH) were then determined and values for the extracts ranged from 177 to $4458 \mu \mathrm{g} / \mathrm{mL}$. Extracts prepared using polar solvents had significantly higher antioxidant capacities than others and may have clinical applications in any disease characterized by a chronic state of oxidative stress, such as sickle cell anemia. Further work will involve the assessment of these extracts in a sickle cell model of oxidative stress.
\end{abstract}

Keywords: Moringa oleifera; DPPH; antioxidant activity; oxidative stress; sickle cell anemia

\section{Introduction}

The Moringa oleifera plant, which is also known as "Marengue" in Jamaica, is one of the 13 species in the Moringa genus. Other species include Moringa stenopetala and Moringa ovalifolia. Moringa oleifera is also called the Horseradish tree, and like horseradish it possesses a taproot system that supports the umbrella-like canopy of the trunk, leaves, and branches [1,2]. The leaves are tripinnate and grow with a fragile feather-like drooping crown. Fragrant flowers grow as spreading auxillary panicles and are yellowish white, and when fertilized produce pods resembling that of the common bean (Phaseolus vulgaris), commonly referred to as string beans or snap beans. Similar to stringbeans, the pods are initially green; however, as Moringa pods mature, they become brown and thicker [2]. In Jamaica, flowers and consequently pods are produced at an increased rate during the rainy season, 
although flowering and fruiting occurs throughout the year. The plant seems to prefer the drier climate of the southern areas in Jamaica but also grows in the north [3]. Several non-governmental organizations including the Food and Agricultural Organization (FAO), Educational Concerns for Hunger Organization (ECHO), Church World Service, and Trees for Life have endorsed Moringa as a nutritional gold mine for tropical areas due to its nutritional content and its ability to grow in tropical and drought affected areas [4,5].

Moringa oleifera is native to the Himalayas and grows well in sub-tropical and tropical regions of the world. It is widely used in ethnobotany and is thought to cure a variety of diseases [4]. Moringa has long been a part of Ayurvedic medicine in India and is understandably referred to as the "Miracle Tree". All parts of the Moringa plant are edible, with leaves and pods used most frequently. The leaves of the plant are utilized as a nutritional supplement, are thought to boost the immune system as well as energy levels, and are known to have anti-inflammatory as well as antioxidant properties. In Jamaica, Moringa is used in the preparation of hot and cold beverages (teas and juices) and as meals in many households. The interest in Moringa started in the 2000s, and this interest continues today. Various investigations have shown that Moringa contains antioxidants [4,6-8]. Antioxidants are useful in the management of oxidative stress in the body [9]. Moringa could potentially be used to improve the clinical condition of persons with oxidative stress conditions such as sickle cell anemia (SCA). Oxidative stress is the result of an imbalance between reactive oxidative species (ROS) and antioxidant components in the body. ROS can potentially damage cells in the body, destabilizing the cell integrity by reacting with cellular components [9]. Antioxidant components are designed to reduce ROS [9]. The body produces ROS as a part of its normal metabolic processes and consequently has biological mechanisms to counteract oxidation [10].

In healthy people, the antioxidant system usually restores balance easily by reducing ROS when formed [9]. People with SCA experience a relatively higher oxidant load due to factors including the increased frequency of erythrocyte destruction (which results in excessive free heme, a potential oxidant). People with SCA also seem to have an increased metabolic rate, which in turn increases the production of oxidants. This increased oxidant production results in an imbalance of oxidants compared to antioxidants causing oxidative stress [10,11]. Sickle cell anemics therefore have higher levels of ROS due to the inability of their antioxidant system to compensate for the abnormal free heme plasma levels. This results in inflammation and chronic organ damage $[9,10]$.

In Jamaica, 1 in 300 persons are estimated to have SCA in Jamaica. People with SCA experience a variety of symptoms, the consequences of which could be serious and expensive for Jamaicans. Sickle cell anemics often experience sickling crises, for which the disease is named. Leg ulcers, splenomegaly, stroke, pulmonary hypertension, and other conditions may also occur. Inflammation is an underlying symptom associated with many conditions.

People with SCA are treated symptomatically. Symptoms include pain and infections, which are treated with analgesics and antibiotics, respectively. SCA is prevalent in African and Caribbean nations, developing countries with limited resources. Moringa is a tropical plant that grows easily in these countries and is therefore readily accessible [4]. The use of the plant would be a cost-effective way of combating SCA by reducing oxidative stress. There appears to be no evidence in the literature of antioxidant activity testing of the Jamaican grown Moringa plant. This study was initiated to determine the antioxidant activity of Moringa plants grown in Jamaica.

\section{Results}

Initial extraction with ethanol (E) resulted in 37\% recovery. Further fractionation using various solvents, namely hexane, chloroform, butanol, and water was performed. In relation to the ethanol extract, the percentage recovery for the solvent extracts was as follows: hexane-E1 (48\%), chloroform-E2 $(1.75 \%)$, butanol-E3 $(9.46 \%)$, and water-E5 (18.26\%). DPPH reduction percentages are shown in Figure 1. The slope of the DPPH reduction percentage plot was used as an indicator of antioxidant capacity. 
Moringa extracts E3 and E5 have higher slopes compared to E1 and E2 (Figure 1); therefore, E3 and E5 have higher antioxidant capacities compared to E1 and E2.

$\mathrm{IC}_{50}$ values, representing the sample concentration at which $50 \%$ of the DPPH radical has been reduced, were calculated from the DPPH reduction percentages. There is an inverse relation between $\mathrm{IC}_{50}$ values and antioxidant activities; this means that lower $\mathrm{IC}_{50}$ values indicate a higher antioxidant capacity. Extracts E2 and E1 had IC 50 values of $1604 \mu \mathrm{g} / \mathrm{mL}$ and $4477 \mu \mathrm{g} / \mathrm{mL}$, respectively, while extracts E, E3, E4, E5, and A had IC 50 values of $832.8 \mu \mathrm{g} / \mathrm{mL}, 172.6 \mu \mathrm{g} / \mathrm{mL}, 1085 \mu \mathrm{g} / \mathrm{mL}, 516.9 \mu \mathrm{g} / \mathrm{mL}$, and $1003 \mu \mathrm{g} / \mathrm{mL}$, respectively. Based on the graph (Figure 1) showing the percentages of DPPH reduction, extracts E3 and E5 possessed more effective antioxidative capacity compared to the other extracts. Figure 2 also shows that the $\mathrm{IC}_{50}$ values of extracts $\mathrm{E} 3$ and $\mathrm{E} 5$ were lower compared to the other extracts.

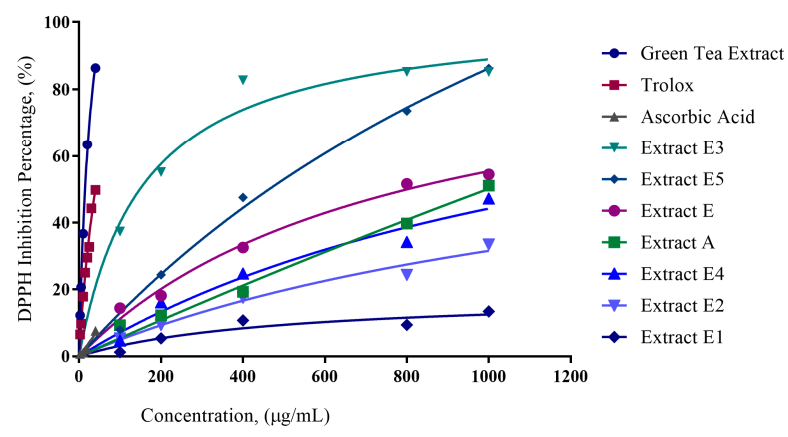

Figure 1. DPPH reduction percentage of Trolox, ascorbic acid, green tea, and the Moringa oleifera leaf extracts A, E, E1-5 after 30 minutes. DPPH Reduction Percentage gradients for extracts E3 and E5 $(0.147 ; 0.082)$ were higher compared with the other extracts, particularly E1 and E2 $(0.011 ; 0.029)$. E5 and E3 had gradients over 3-7 times greater than E2 and E1, respectively.

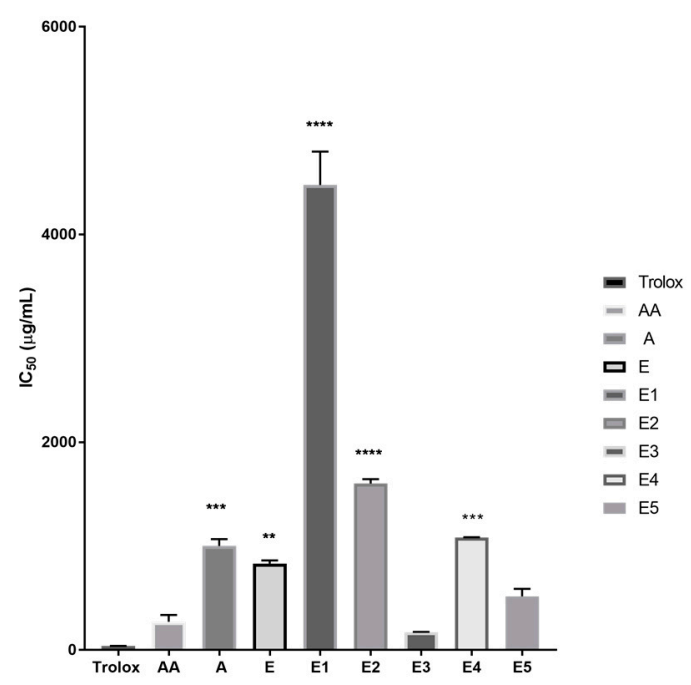

Figure 2. $\mathrm{IC}_{50}$ values of ascorbic acid (AA) compared with Trolox and Moringa leaf extracts A, E, and E1-E5. Statistical significance was calculated using one-way analysis of variance (ANOVA) followed by Dunnett's post-hoc test using GraphPad Prism statistical software; values of $p<0.05$ were considered statistically significant. Significant values were denoted as follows: ${ }^{* *} p \leq 0.01$; ${ }^{* * *} p \leq 0.001 ;{ }^{* * * *} p \leq 0.0001$. Ascorbic acid had an $\mathrm{IC}_{50}$ value of $272 \mu \mathrm{g} / \mathrm{mL}$. Extracts E2 and E1 had $\mathrm{IC}_{50}$ values of $1604 \mu \mathrm{g} / \mathrm{mL}$ and $4477 \mu \mathrm{g} / \mathrm{mL}$ respectively, while extracts E, E3, E4, E5, and A had approximately 2-6 times lower $\mathrm{IC}_{50}$ values of $833 \mu \mathrm{g} / \mathrm{mL}, 173 \mu \mathrm{g} / \mathrm{mL}, 1085 \mu \mathrm{g} / \mathrm{mL}, 517 \mu \mathrm{g} / \mathrm{mL}$, and $1003 \mu \mathrm{g} / \mathrm{mL}$, respectively. 


\section{Discussion}

Antioxidant activity of Moringa oleifera leaf extracts from Jamaica was assessed using the 2,2-diphenyl-1-picrylhydrazyl (DPPH) assay [6,12]. This seems to be the first study of antioxidant activity using Moringa sourced from Jamaica, as the literature tends to lack any such information. It should be noted that these extracts were produced from a direct ethanolic extraction of the Moringa leaves. Typically, when antioxidant principles are being extracted from samples or when antioxidant tests are being conducted, an alcoholic solvent, aqueous solvent, or a combination of both is used as the extracting agent $[6,13-15]$.

The crude extract E was sequentially extracted using solvents of different polarities. This allowed for the sequential separation of compounds based on the affinity to the solvent. This further subdivision of extracts provided a clearer picture as to which solvents have the greater capacity to accumulate antioxidants as well as concentrating the antioxidant extracts to smaller fractions. Extracts E1 and E2 were produced using hexane and chloroform, respectively. Extracts E3 and E5 were produced using polar solvents, namely butanol and water, respectively. In Figure 1, the DPPH reduction percentage was calculated for samples and controls.

The $\mathrm{IC}_{50}$ values for each sample was calculated to show the concentration of sample needed to reduce $50 \%$ of the $\mathrm{DPPH}$ in the assay. Low $\mathrm{IC}_{50}$ values correspond to high antioxidant activity. The $\mathrm{IC}_{50}$ values show that E3 $<$ E5 $<$ E $<\mathrm{A}<\mathrm{E} 4<\mathrm{E} 2<\mathrm{E} 1$ (Figure 2). Both E1 and E2 showed lower antioxidant activities than other extracts, with E1 being the lowest. This could be explained by the fact that hexane was the most non-polar solvent used in the experiment. Antioxidant compounds are known to accumulate in polar solvents and it is understandable that they would not be present in substantial amounts in an extract produced from hexane. Chloroform is more polar than hexane, so the increased antioxidant activity seen in extract E2, compared with extract E1 (hexane), is expected [16,17]. This data also suggests that liquid-liquid extraction of crude extract E with low polarity solvents, hexane and chloroform, was effective in separating fractions with high antioxidant potential, thus producing a more concentrated antioxidant fraction (the residual fraction after extraction with chloroform). This fraction when extracted further produced extracts E3 and E5, which had higher antioxidant capacity compared to the extracts.

Extract $\mathrm{E} 3$ had the highest antioxidant activity since it had the lowest $\mathrm{IC}_{50}$ value. It is notable that extract E3 possessed a similar $\mathrm{IC}_{50}$ value to ascorbic acid (vitamin $\mathrm{C}$ ), a known antioxidant, which suggests that extract E3 could be a valuable antioxidant. Extract E had a lower antioxidant activity than extracts E3 and E5 based on the $\mathrm{IC}_{50}$ value; however, it still had a good antioxidant activity compared with ascorbic acid. These results suggest that the components responsible for antioxidant activity in Moringa leaves are polar compounds. The values for Moringa compared with the standard Trolox were not an exact match compared with values found in the literature; however, when the values were normalized as a ratio, the values correlated with results obtained by Chumark et al. (2008) [18]. Chumark et al. also showed that Trolox has a lower $\mathrm{IC}_{50}$ value compared to the Moringa extract, with Moringa being 35 times less potent than Trolox. In fact, it seems that the Jamaican Moringa had comparatively better antioxidant activity, as this study showed Moringa was only four times less potent than Trolox. At the time of this study, Moringa could be found in only a few regions of the island, and the material analyzed was from a single region [3]. Further studies are needed to test the Moringa leaves from other regions in Jamaica extracted under the same conditions to determine if the antioxidant activity differs from parish to parish, possibly depending on the nature of the soil. All leaves used in this assay were harvested at the same time. Researchers in Pakistan, Iqbal and Bhanger (2006), assessed the variations in the antioxidant activity of Moringa leaves in different seasons and sample locations and found that the antioxidant activity varied based on season and locations of the plants from which the samples were obtained [19]. However, it is important to note that Pakistan has a larger variation of climatic conditions compared to Jamaica. It is possible that the plants were affected by the cooler and/or drier conditions experienced there. In Jamaica, given the low variability in climatic conditions, it is possible that the Jamaican plants would not have significant differences in 
antioxidant activities based on the location and time of harvest. Additionally, it is also possible that Jamaican Moringa has adapted over the years to the moderate climate experienced in Jamaica compared with Pakistan's climate. Although the antioxidant activities of Jamaican Moringa leaves should be independent of the harvesting locations, this information is not known. This data would be significant if Moringa were to be exploited commercially. It may also be useful to investigate antioxidant activities of Moringa plants throughout the Caribbean, where the climatic conditions are generally similar but the nature of the soil may vary.

Siddharaj and Becker (2003) have shown that different agroclimatic conditions can result in different antioxidant capacities [6]. In his results, it was seen that India had the best antioxidant capacity compared to samples taken in Central America (Nicaragua) and Africa. This study, however, did not focus on the soil quality, which is another factor that could affect the quality of bioactive principles in plants. Forster and colleagues (2015) assessed the impact of sulfur (a soil factor) compared to water availability. In the field, water availability would typically be determined by rainfall, which is a climatic factor [20]. This study showed that the availability of sulfur had a positive impact on the presence of the beneficial bioactive principles in Moringa. There seems to be no direct study yet done on the effect of other soil factors such as $\mathrm{pH}$, soil nutrient levels, and soil type on the antioxidant capacity in Moringa leaves. The studies mentioned above however, seem to allude to the premise that these factors could be responsible for differences between the antioxidant activity seen in different countries.

It should also be noted that the genotype of Moringa in Jamaica has not been elucidated. There is therefore no concrete evidence to indicate whether Jamaican Moringa is a different cultivar compared to those in Asia or Africa. Moringa was initially introduced to Jamaica in 1784; however, Asian and African migrants have entered Jamaica over the years, and it is quite possible that these immigrants may have brought different varieties or cultivars of Moringa oleifera. This means that there could be several cultivars of Moringa oleifera present in Jamaica as well. For example, a variety with completely white flowers and a different flavor profile has been noted in Jamaica.

Ndhlala and colleagues (2014) analyzed 13 Moringa cultivars from four regions (Thailand, Taiwan, United States of America, and South Africa) for antioxidant capacity. The data showed that the samples from Thailand had the best antioxidant capacity, whereas samples from South Africa (Silver Hill) had the lowest activity [21]. Ndhlala and others (2014) postulated among other things that climatic/environmental differences between the regions could be responsible for the variations seen [21]. Moringa has been present in Thailand for several decades, and it is possible that the antioxidant profile is due to the plant's adaptation to its environs [21]. Both Jamaica and Thailand have tropical climates; similarly, the environmental conditions under which the Jamaican Moringa plant is grown could have a positive effect on its antioxidant capacity. A comparison between samples from different agroclimatic origins would be beneficial to determine if this postulation is a valid claim. Analyses of soil factors would also be beneficial in providing a broader picture of the impact of environmental conditions on antioxidant capacity in Moringa oleifera.

\section{Methods and Materials}

\subsection{Reagents}

Methanol (HPLC grade), ethanol, butanol, hexane, and chloroform (ACS grade), ascorbic acid, and 2,2-diphenyl-1-picrylhydrazyl (DPPH) free radical were obtained from Sigma-Aldrich (Saint Louis, Missouri, USA). Green tea extract (pre-standardized to 50\% epigallocatechin gallate) was obtained from HerbStoreUS (Walnut, CA, USA).

\subsection{Extraction of Moringa oleifera Leaves}

Moringa oleifera leaves were prepared according to the method in Luo et al. (2011) and Oyugi et al. (2009) with modifications [14,22]. The leaves were harvested, rinsed with clean water, and air-dried at room temperature overnight. The leaves were then placed in an oven at $40{ }^{\circ} \mathrm{C}$ and left until completely 
dry. The leaves were milled into a fine powder. The milled leaf samples $(20 \mathrm{~g})$ were subjected to soxhlet extraction using $80 \%$ ethanol: water mixture $(250 \mathrm{~mL})$. The resulting solution was dried in vacuo and stored at $4{ }^{\circ} \mathrm{C}$ until further analysis. This extract was called E. Different fractions were obtained by sequential washing with different solvents (Figure 3). Extract $\mathrm{E}$ was further purified by washing with non-polar and polar solvents. The dried extract $\mathrm{E}$ was re-suspended in $250 \mathrm{~mL}$ of water. This aqueous extract was subsequently extracted with $250 \mathrm{~mL}$ of hexane, chloroform, and butanol, respectively. The respective solvent was decanted after each extraction and dried in vacuo. Extracts were labeled as follows: E1: hexane; E2: chloroform; E3: butanol; E4: interphase between E5 and E3; E5: remaining water fraction. For the production of Sample A, double distilled water was added to the milled leaves, which were subsequently heated for $24 \mathrm{~h}$ with constant stirring. The decoction was filtered and the filtrate lyophilized. All samples were stored at $4{ }^{\circ} \mathrm{C}$ until further analysis.

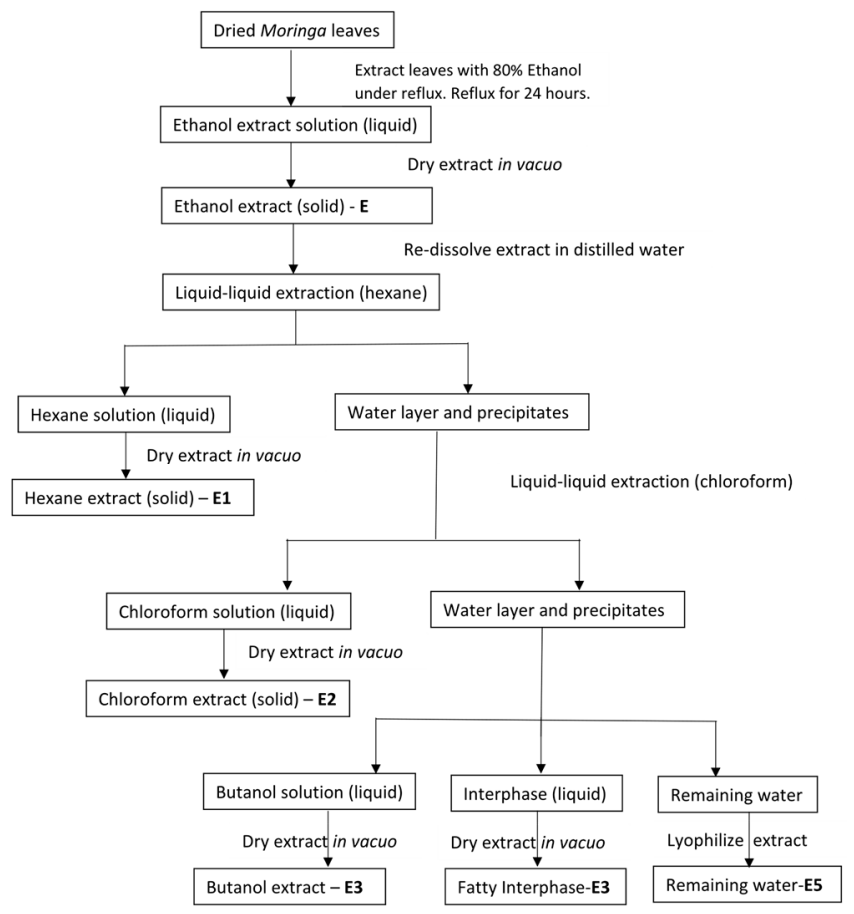

Figure 3. Schematic diagram of the ethanolic extraction process of Moringa oleifera leaves.

\subsection{DPPH Radical Scavenging Assay}

The antioxidant capacity of the Moringa oleifera leaf extracts were analyzed for reductive capacity using the 2,2-diphenyl-1-picrylhydrazyl (DPPH) assay [6,12]. DPPH is a stable free radical that absorbs strongly at $517 \mathrm{~nm}$. When exposed to an antioxidant, it degrades to a light-yellow color that does not absorb at $517 \mathrm{~nm}$. Therefore, the antioxidant activity of a substance can be analyzed based on the how strongly DPPH is absorbed at $517 \mathrm{~nm}$. This assay was done using Trolox, a vitamin E analogue with well-documented antioxidant activity, as the main control for comparison with the extracts. Two additional controls, ascorbic acid and green tea extract, known chemical and herbal antioxidants, respectively, were used to compare the extracts' antioxidant capacities as they are typical antioxidants found in nature and are weaker than Trolox [15]. The green tea extract was pre-standardized to contain $50 \%$ epigallocatechin gallate, the main antioxidant in green tea.

\subsubsection{Experimental Procedure}

Controls and extracts E and E1-E5 were diluted to appropriate concentrations in methanol to ascertain the antioxidant capacity of all compounds in a linear range. The extracts were diluted to concentrations of $100,200,400,800$, and $1000 \mu \mathrm{g} / \mathrm{mL}$. The standard (Trolox) was diluted to 
concentrations of 2.5, 5, 10, 15, 20, 25, 30, and $40 \mu \mathrm{g} / \mathrm{mL}$. The controls (ascorbic acid and green tea extract) were diluted to concentrations of 2.5, 5, 10, 20, and $40 \mu \mathrm{g} / \mathrm{mL} ; 0.1 \mathrm{mM} \mathrm{DPPH}$ in methanol was used and prepared fresh daily.

Controls and extracts were analyzed according to the method of Williams et al. (2006) with some modifications. The controls and extracts ( $40 \mu \mathrm{L}$ each) were reacted with DPPH (200 $\mu \mathrm{L}$ each) in 96-well microplates for $30 \mathrm{~min}$ in the dark. A blank using methanol, in place of the sample, was also prepared and incubated with the samples. After incubation, the absorbance of samples was read using a Spectromax Pro 250 (Molecular Devices, Sunnnydale Ca.) microplate reader at $517 \mathrm{~nm}$.

The mean optical density of the sample was used to calculate the DPPH reduction (inhibition), which is the percentage of DPPH that was neutralized by the antioxidants present in the added samples.

The equation below was used to calculate this percentage:

The DPPH reduction percentage is calculated as follows:

$$
\left[\left(\mathrm{A}_{\mathrm{O}}-\mathrm{A}_{\mathrm{S}}\right) / \mathrm{Ao}\right] \times 100
$$

where $A_{O}$ is the blank absorbance, and $A_{S}$ is the sample

The results were tabulated and presented in graphical format.

The $\mathrm{IC}_{50}$ values were calculated from the $\mathrm{DPPH}$ reduction percentages and referred to the concentration of sample (in $\mu \mathrm{g} / \mathrm{mL}$ ) required to reduce $50 \%$ of the DPPH present in the assay.

\subsubsection{Statistical Analysis}

Mean \pm SEM was calculated from replicates of three or more for each sample. Significant differences between the values were calculated using Dunnett's post-hoc test with GraphPad Prism 5.0. Values of $p<0.05$ was considered statistically significant.

Acknowledgments: This research was funded by grants from the Biotechnology Centre and Office of Graduate Studies University of the West Indies, Mona, Jamaica, the Eagle-i consortium, supported by NCRR (award \#U24 RR 029825), as well as the National Institute on Minority Health and Health Disparities of the National Institutes of Health under Award Number G12MD007581. The content is solely the responsibility of the authors and does not represent the official views of the National Institutes of Health.

Author Contributions: Racquel Wright, Ken Lee, Jacqueline Hibbert, Andrew Wheatley and Helen Asemota conceived and designed the experiments. Racquel Wright performed the experiments. Andrew Wheatley, Hyacinth Hyacinth, Jacqueline Hibbert and Ken Lee supervised experimentation. Ken Lee, Andrew Wheatley and Jacqueline Hibbert contributed reagents/materials/analysis tools. Helen Asemota, Marvin Reid and Jacqueline Hibbert reviewed and revised the paper. Racquel Wright wrote the paper.

Conflicts of Interest: The authors declare no conflict of interest. The funding sponsors had no role in the design of the study; in the collection, analyses, or interpretation of data; in the writing of the manuscript; or in the decision to publish the results.

\section{References}

1. Adams, C.D. Flowering Plants of Jamaica; University of the West Indies: Mona, Jamaica, 1972; pp. $310-311$.

2. Roloff, A.; Weisgerber, H.; Lang, H.; Stimm, B. Moringa Oleifera Lam., 1785; Enzyklopädie der Holzgewächse: Weinheim, Germany, 2009.

3. Grant, D. (Forestry Department, Ministry of Agriculture, St. Andrew, Jamaica). Personal communication, 2009.

4. Fahey, J.W. Moringa oleifera: A review of the Medical evidence for its nutritional, Therapeutic and prophylactic properties. Part 1. Trees Life J. 2005, 1, 1-21.

5. FAO Promotes Moringa Cultivation in Ethopia and Phillipines. 2014. Available online: http://www.intracen. org/itc/blogs/market-insider/FA-Promotes-Moringa-Cultivation-in-Ethiopia-and-Philippines/ (accessed on 30 August 2017).

6. Siddhuraju, P.; Becker, K. Antioxidant Properties of Various Solvent Extracts of Total Phenolic Constituents from Three Different Agroclimatic Origins of Drumstick Tree (Moringa oleifera Lam.) Leaves. J. Agric. Food Chem. 2003, 51, 2144-2155. [CrossRef] [PubMed] 
7. Dahiru, D.; Onubiyi, J.A.; Umaru, H.A. Phytochemical screening and antiulcerogenic effect of Moringa oleifera aqueous leaf extract. Afr. J. Tradit. Complement. Altern. Med. 2006, 3, 70-75. [CrossRef]

8. Sreelatha, S.; Padma, P.R. Antioxidant Activity and Total Phenolic Content of Moringa oleifera Leaves in Two Stages of Maturity. Plant Foods Hum. Nutr. 2009, 64, 303-311. [CrossRef] [PubMed]

9. Wood, K.C.; Granger, D.N. Sickle cell disease: Role of reactive oxygen and nitrogen metabolites. Clin. Exp. Pharmacol. Physiol. 2007, 34, 926-932. [CrossRef] [PubMed]

10. Fasola, F.; Adedapo, K.; Anetor, J.; Kuti, M. Total antioxidants status and some hematological values in sickle cell disease patients in steady state. J. Natl. Med. Assoc. 2007, 99, 891-894. [PubMed]

11. Nagababu, E.; Fabry, M.E.; Nagel, R.L.; Rifkind, J.M. Heme degradation and oxidative stress in murine models for hemoglobinopathies: Thalassemia, sickle cell disease and hemoglobin C disease. Blood Cells Mol. Dis. 2008, 41, 60-66. [CrossRef] [PubMed]

12. Williams, L.; Hibbert, S.; Porter, R.; Bailey-Shaw, Y.; Green, C. Jamaican plants with in vitro anti-oxidant activity. In Biologically Active Natural Products for the 21st Century; Williams, L., Ed.; Research Signpost: Trivandrum, India, 2006; pp. 1-12.

13. Manian, R.; Anusuya, N.; Siddhuraju, P.; Manian, S. The antioxidant activity and free radical scavenging potential of two different solvent extracts of Camellia sinensis (L.) O. Kuntz, Ficus bengalensis L. and Ficus racemosa L. Food Chem. 2008, 107, 1000-1007. [CrossRef]

14. Luo, X.; Jiang, Y.; Fronczek, F.R.; Lin, C.; Izevbigie, E.B.; Lee, K.S. Isolation and structure determination of a sesquiterpene lactone (vernodalinol) from Vernonia amygdalina extracts. Pharm. Boil. 2011, 49, 464-470. [CrossRef] [PubMed]

15. Das, N.; Islam, M.E.; Jahan, N.; Islam, M.S.; Khan, A.; Islam, M.R.; Parvin, M.S. Antioxidant activities of ethanol extracts and fractions of Crescentia cujete leaves and stem bark and the involvement of phenolic compounds. BMC Complement. Altern. Med. 2014, 14, 1-9. [CrossRef] [PubMed]

16. Harborne, J.B. Phytochemical Methods: A Guide to Modern Techniques of Plant Analysis, 2nd ed.; Chapman and Hall: London, UK, 1972.

17. Trease, G.E.; Evans, W.C. Pharmacognosy, 10th ed.; Bailliere Tindall: London, UK, 1972.

18. Chumark, P.; Khunawat, P.; Sanvarinda, Y.; Phornchirasilp, S.; Morales, N.P.; Phivthong-ngam, L.; Klai-upsorn, S.P. The in vitro and ex vivo antioxidant properties, hypolipidaemic and antiatherosclerotic activities of water extract of Moringa oleifera Lam. leaves. J. Ethnopharmacol. 2008, 116, 439-446. [CrossRef] [PubMed]

19. Iqbal, S.; Bhanger, M.I. Effect of season and production location on antioxidant activity of Moringa oleifera leaves grown in Pakistan. J. Food Compos. Anal. 2006, 19, 544-551. [CrossRef]

20. Förster, N.; Ulrichs, C.; Schreiner, M.; Arndt, N.; Schmidt, R.; Mewis, I. Ecotype variability in growth and secondary metabolite profile in Moringa oleifera: Impact of sulfur and water availability. J. Agric. Food Chem. 2015, 63, 2852-2861. [CrossRef] [PubMed]

21. Ndhlala, A.R.; Mulaudzi, R.; Ncube, B.; Abdelgadir, H.A.; du Plooy, C.P.; van Staden, J. Antioxidant, antimicrobial and phytochemical variations in thirteen Moringa oleifera Lam. Cultivars. Molecules 2014, 19, 10480-10494. [CrossRef] [PubMed]

22. Oyugi, D.A.; Luo, X.; Lee, K.S.; Hill, B.; Izevbigie, E.B. Activity markers of the anti-breast carcinoma cell growth fractions of Vernonia amygdalina extracts. Exp. Boil. Med. 2009, 234, 410-417. [CrossRef] [PubMed]

(C) 2017 by the authors. Licensee MDPI, Basel, Switzerland. This article is an open access article distributed under the terms and conditions of the Creative Commons Attribution (CC BY) license (http:/ / creativecommons.org/licenses/by/4.0/). 